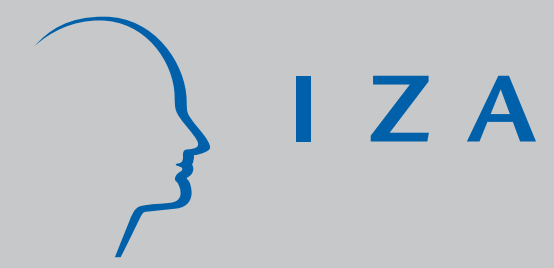

IZA DP No. 1100

The Success of J ob Applications:

A New Approach to Program Evaluation

Armin Falk

Rafael Lalive

J osef Zweimüller

April 2004 


\title{
The Success of Job Applications: A New Approach to Program Evaluation
}

\author{
Armin Falk \\ IZA Bonn and University of Bonn \\ Rafael Lalive \\ University of Zurich and IZA Bonn \\ Josef Zweimüller \\ University of Zurich and IZA Bonn
}

Discussion Paper No. 1100

April 2004

IZA

P.O. Box 7240

53072 Bonn

Germany

Phone: +49-228-3894-0

Fax: +49-228-3894-180

Email: iza@iza.org

\begin{abstract}
Any opinions expressed here are those of the author(s) and not those of the institute. Research disseminated by IZA may include views on policy, but the institute itself takes no institutional policy positions.

The Institute for the Study of Labor (IZA) in Bonn is a local and virtual international research center and a place of communication between science, politics and business. IZA is an independent nonprofit company supported by Deutsche Post World Net. The center is associated with the University of Bonn and offers a stimulating research environment through its research networks, research support, and visitors and doctoral programs. IZA engages in (i) original and internationally competitive research in all fields of labor economics, (ii) development of policy concepts, and (iii) dissemination of research results and concepts to the interested public.
\end{abstract}

IZA Discussion Papers often represent preliminary work and are circulated to encourage discussion. Citation of such a paper should account for its provisional character. A revised version may be available on the IZA website (www.iza.org) or directly from the author. 


\section{ABSTRACT}

\section{The Success of Job Applications: A New Approach to Program Evaluation*}

In this paper, we suggest a novel approach to program evaluation that allows identification of the causal effect of a training program on the likelihood of being invited to a job interview under weak assumptions. The idea is to measure the program-effects by pre- and posttreatment data that are very close in time for the same individual. Our approach provides useful information on both, average effects of the program as well as information on potential differences in the effects of the program by type of vacancy or by individual.

JEL Classification: $\quad$ 138, C93

Keywords: evaluation, active labour market program, correspondence testing, field experiments

Corresponding author:

Armin Falk

IZA Bonn

P.O. Box 7240

53072 Bonn

Germany

Email: falk@iza.org

\footnotetext{
* We are grateful to Bernd Fitzenberger, Ernst Fehr, Lorenz Götte, Rudolf Winter-Ebmer, and Jan C. van Ours, two anonymous referees, and participants at the HUI seminar 2001 for helpful comments on an earlier draft of this paper. A substantial part of this paper was rewritten while Rafael Lalive was visiting IFAU, Uppsala, Sweden. We thank Manuel Gonzales for excellent research assistance and Maria Hermann for checking the manuscript.
} 


\section{Introduction}

The best solution to the evaluation problem lies in improving the quality of the data on which evaluations are conducted and not in the development of formal econometric methods to circumvent inadequate data.

(Heckman/Smith 1999, p. 3)

There is no doubt that in the presence of tight government budgets credible policy evaluation is very important. There is also no doubt, however, that the evaluation of policy programs involves fundamental methodological difficulties. In this paper we suggest a new approach to the evaluation of labour market programs that relies on a novel approach and on self-collected data that help to identify the causal program effect under rather weak assumptions.

We analyse the impact of participation in active labour market programs that are offered to unemployed individuals as part of the Swiss labour market policy. Since the second revision of the national unemployment insurance act in 1997, the unemployed are supposed to take an active part in improving their skills and job fitness. The different measures can be divided into three broad categories: training programs, public employment programs and wage subsidies. ${ }^{2}$ This paper focuses on a particular training program, which is meant to improve basic computer skills. These courses last between two and three weeks and teach basic word processing or spreadsheet calculation skills. Participating individuals receive a course certificate upon completion of the course.

To assess the impact of the program, our procedure was as follows: First, we recruited unemployed persons who participated in the computer courses. Then we sent out applications for these people before they finished their course. A second wave of applications was sent after the participants had successfully completed the course and had received a certificate. The new applications were exactly the same as before with the only exception that this time the application also contained the course certificate. The impact of the program is measured by the firms' responses. We check whether the probability of becoming invited for a job interview is different for the applications with certificate than for those without.

The method we suggest in this paper has at least two major advantages compared to the existing techniques of policy evaluation. First, the pre-post comparison allows us to net out time-invariant individual characteristics. Due to the fact that we observe pre- and post

\footnotetext{
${ }^{2}$ For details of the program see the evaluation studies by Gerfin and Lechner (2002) or Lalive, Van Ours, and Zweimüller (2002).
} 
treatment outcomes within a period of a few weeks, we do not face the problem of varying labour market conditions that usually makes pre-/post comparisons problematic. The time proximity of treatment and control observations ensures that job chances of the individuals are not significantly different between treatment and control states.

The second major advantage of our approach is that the application process is not influenced by the participants. The set-up of our study rules out any changes in search intensity and/or wage aspirations, because the researcher controls the application process. In previous studies it has been shown that the search intensity may be influenced negatively by course participation, which in turn produces a possible confound for the evaluation of the program (Calmfors, Forslund and Hemström, 2001). The same holds for changed reservation wages or aspiration levels in general. It may well be that participating in a policy measure raises the aspirations for a new job.

According to our results, the probability of becoming invited to a job interview is, on average, negative but insignificant. Moreover, we find that a significant negative mean impact of the program can be assessed for vacancies that require good computer skills (compared to vacancies that do not require such skills). This result is counterintuitive on first sight. A possible explanation, however, is that the participation in a very basic computer course may actually inform the hiring firm about the absence rather than about the presence of profound computer skills.

In the next section we describe the procedure and the design of our study. Section 3 reviews some of the related literature. Section 4 discusses the identifying assumption and compares it to such assumptions invoked in cross-section observational studies. Section 5 describes the data and contains results on the effect of computer courses on the probability of being invited to a job interview. Section 6 concludes.

\section{Design of the Study}

Our study was designed to investigate the effect of computer courses on the chances to be invited to a job interview. These computer courses are part of the active labour market policy in Switzerland. They last for about two to three weeks and teach basic computer skills, e.g., the use of operating system software and an introduction to word processing or spreadsheet calculation programs. Assessing the effectiveness of the programs is interesting as the aim of the Swiss active labor market policy is fast re-integration of job seekers into the "primary" 
labor market. Thus, when we evaluate the chances of being invited to a job interview, we shed light on the first stage of process by which computer courses may affect re-integration.

The potential effects of these short term courses may not be expected to be that large, given that one year of regular education results in some 5-10\% increase in wages. However, this comparison is potentially problematic. First, course participation might turn out to be very beneficial for participants if the courses teach key qualifications, i.e., if participants acquire knowledge, which is of particular importance for finding a job. Second, an important problem of joblessness may be due to information asymmetries between job seekers and employers. If signaling effects are important, even short programs can have big effects (see, Tyler et al. (2000). ${ }^{3}$

To recruit participants for our study we contacted various educational institutions that offer the courses and asked for the permission to recruit their course participants. We then went to the corresponding courses and informed the course participants about our study. This information included a short description of the aims of the study and all procedural details. Course participants were also informed that in case of participating in our study they were to receive a compensation of CHF $200(\sim € 130)$.

All individuals interested in participating in the study were individually invited to our institute for a first appointment. They had to bring their CV, copies of diplomas, other relevant certificates and letters of recommendation, i.e., all documents that are enclosed in a typical job application in Switzerland. Together with each participant we discussed what kind of jobs he or she usually applies to. Given the individual profile we searched for vacancies on the internet and in "Tages-Anzeiger", the main newspaper in the Zurich area, for the type of jobs that participants in the study are looking for. Specifically, during a period of one week, we recorded all vacancies that fit to the individual profile of the participant. We then prepared his or her job applications including a cover letter, the CV and all documents about education and previous positions. Prior to sending the application to the corresponding firms, the applicant looked through all applications and signed them. This first set of applications was sent without a computer course certificate.

When a participant had finished his or her course and had received the course certificate we prepared a second set of applications. These applications were exactly the same as before, with the only exception that now the just recently acquired basic computer skills were 
mentioned in the application letter and a copy of the relevant certificate(s) was included. Again the participant looked through the applications and signed them before they were sent to the firms. ${ }^{4}$

The participants in our study had to keep track of all firm responses. To standardize this information, participants were given a form where they had to insert, e.g., the firm's name they had applied to, the date at which the firm reacted and whether the firm wished an interview or not. In case a participant received an invitation, it was at the participant's discretion to accept the interview or to deny it. After the participant sent us the completed form the person was paid the CHF 200. Most firms that received an application letter usually answered within a period of three weeks ( 83 percent). ${ }^{5}$

Together with the applicant's CV and the completed forms we have the following data: (i) The firm's response (wishes an interview, wishes no interview, wants further information, no response after three weeks), (ii) individual characteristics of the applicant, (iii) the firm's job advertisement (including special requirements for applicant, like computer or language skills, blue collar or white collar job, firm's name and type of industry/sector, size of the advertisement in the newspaper, hours of work, the date we sent the application to the firm), and (iv) the date the firm contacted the applicant.

\section{Related Literature}

Our design is similar to the so-called 'correspondence testing' method. According to the latter, matched pairs of applicants apply for a job. The two applicants differ only with respect to a treatment variable like sex or race. The researcher checks, whether the invitations of the two persons differ and takes this as evidence for a treatment effect. These studies have been conducted to study discrimination issues, such as racial discrimination (e.g., Firth 1981, Riach and Rich 1991), sex discrimination (e.g., Neumark 1996, Riach and Rich 1995, Weichselbaumer 2004) and unemployment stigma (Oberholzer-Gee 2000). To our knowledge no such type of study has yet been applied to program evaluation.

\footnotetext{
${ }^{3}$ See Tyler et al. (2000) evaluating the effects of the graduate equivalence diploma (GED) on income. The out of pocket costs to take the GED are about US\$40. Nevertheless, it is shown that the GED has very strong effects on incomes of young white students.

${ }^{4}$ A previous version of this paper contains an anonymous version of the cover letter and the course certificate of a treated application as well as the cover letter of a control application (Falk et al., 2002).

${ }^{5}$ In case it took longer we told the participant to stop waiting and to send us the completed form without those firms. This restriction changes the interpretation of the dependent variable. We evaluate the effect of computer courses on the firms' responses within the first three weeks since the application has been sent out.
} 
Our procedure differs from the correspondence testing approach in two important ways. First, we do not send matched pairs of applicants to firms. Instead, we send applications of the same person with and without a basic computer course certificate to different firms. This allows perfect control for individual characteristics that is missing in the studies mentioned above. While these studies put much effort in keeping the two applicants as similar as possible (except for the characteristic of interest), they are of course not completely alike. This has given rise to criticism. In his related critique of audit studies, Heckman (1998) notes, e.g., that the chances that all characteristics that might affect productivity are perfectly matched are rather low (p. 108).

The second important difference to the existing correspondence-testing studies is that our study involves no fake or deception whatsoever. In the previous studies known to us there is a varying degree of deception involved. It is, e.g., common practice to completely fake the applicants, i.e., the applicants do not exist at all. In our view this procedure is problematic for various reasons. Most importantly, there is a substantial lack of control. You can never be sure that firms detect deception (e.g., if they try to contact the applicant or a former employer). Moreover, deception makes it impossible to write complete applications. In many European countries and in Switzerland in particular, a meaningful application includes the complete listing of jobs (with the names of former employers and their letters of recommendation) and a detailed record of education (including copies of school and diploma degrees). By using fictitious persons it is not possible to provide all this information in a legal and credible way. A further objection against deception rests on the fact that it imposes a cost on employers who take their time evaluating applications of employees who do not exist. Our study avoids deception. We had only real participants who were actually looking for jobs and who provided us with real documents and biographies.

There is a related empirical literature based on employer surveys that investigates differences in employer hiring by program participation status for Sweden. For instance, Agell and Lundborg $(1995,2003)$ find that employers tend to regard previous unemployment as a stronger signal of low productivity than participation in an active labor market program in two survey studies covering Swedish manufacturing firms. Behrenz (1998) assesses the relevance of unemployment and program participation in hiring. He finds that the proportion of personnel managers unwilling to hire a previously unemployed person is higher than the proportion of managers that would hire the unemployed. For participants in active labor market programs, the conclusion is reversed. 


\section{Identification}

This section addresses the issue under which assumptions our study identifies the causal effect of a computer course certificate on the probability of being invited to a job interview. We also highlight to what extent the present study might be superior to existing approaches in evaluating the causal effect of ALMPs on a particular outcome.

In the following we discuss identification using the model of potential outcomes due to Roy (1951) and Rubin (1974). Define by $Y_{1}$ the random variable taking the value 1 if a job application containing the computer course certificate leads to an invitation to a job interview; let $\mathrm{Y}_{1}$ take the value 0 otherwise. We refer to $\mathrm{Y}_{1}$ as the 'outcome with treatment'. Similarly, define by $\mathrm{Y}_{0}$ the 'outcome without treatment', i.e., the random variable taking the value 1 if an application not containing the computer course certificate leads to an invitation to a job interview. Finally, let $\mathrm{D}$ equal 1 if the job application actually does contain the computer course certificate, and 0 otherwise. This paper is concerned with estimating the effect of a computer course certificate on applications that do contain such a certificate (for the individuals who agreed to participate in the present study), or

$$
\Delta=E\left(Y_{1}-Y_{0} \mid D=1\right)=\operatorname{Pr}\left(Y_{1}=1 \mid D=1\right)-\operatorname{Pr}\left(Y_{0}=1 \mid D=1\right)
$$

This is the change in the probability of being invited to a job interview due to the computer course certificate, the so-called 'effect of treatment on the treated'. ${ }^{6}$ It is useful to introduce additional notation in order to discuss the identifying assumption. Let $\mathrm{x}_{\mathrm{I}}$ refer to all characteristics of the individual that play a role in firms' hiring decisions. These are, for instance, the level of education, the quality of the job application letter, previous work experience of the job seeker, etc. Let $\mathrm{x}_{\mathrm{J}}$ denote all characteristics of the job offer that are observable to individuals who are looking for a new job such as type of skill required, size of the advertisement, working hours, industry of the hiring firm, etc. The identifying assumption underlying this study is

$$
D \mid x_{I}, x_{J} \perp Y_{0}
$$

This conditional independence assumption (CIA) asserts that, conditional on the identity of the job seeker as well as observable characteristics of the job offers, an application letter containing the computer course certificate $(D=1)$ must be independent of the probability of

\footnotetext{
${ }^{6}$ This effect is useful in analyzing whether a program is successful for those who participate in the program. See Heckman et al. (1999) for a definition of different treatment effects and different objectives when pursuing an evaluation study.
} 
invitation $\left(\mathrm{Y}_{0}\right)$. This assumption is justified, intuitively, if there are no unobservables that, simultaneously, determine the presence of a computer course certificate and the probability of an invitation.

CIA implies that the counterfactual outcome, the probability of invitation for treated job applications in the case there has been no computer course certificate, is identical to the corresponding probability for the job applications with no course certificate, i.e.,

$$
\operatorname{Pr}\left(Y_{0}=1 \mid x_{I}, x_{J}, D=1\right)=\operatorname{Pr}\left(Y_{0}=1 \mid x_{I}, x_{J}, D=0\right)
$$

Thus, the effect of the computer course certificate on the probability of invitation is identified using the probability of invitation for those applications not containing the certificate as an estimate of the counterfactual. Given CIA, the effect of treatment on the treated (1) can be estimated by taking the difference between the probability of invitation of treated and the mean probability of invitation of the non-treated (weighted by the distribution of the $\mathrm{x}_{\mathrm{I}}{ }^{\text {s }}$ and $\mathrm{x}_{\mathrm{J}}$ 's in the treated population).

$$
\Delta=\operatorname{Pr}\left(Y_{1} \mid D=1\right)-\int \operatorname{Pr}\left(Y_{0}=1 \mid x_{I}, x_{J}, D=0\right) d F\left(x_{I}, x_{J} \mid D=1\right)
$$

We can now state the methodological advantages of the present study compared to a typical cross-section study more formally. CIA is likely to hold in this study for at least two reasons: First, there is no variation in characteristics of the job application at the individual level $\left(\mathrm{x}_{\mathrm{I}}\right)$ it necessarily follows that there are no unobservable characteristics at the individual level that might determine, simultaneously, the decision of the researcher to include the computer course certificate in the application letter (D), as well as the decision of the firm on extending an invitation to a particular job seeker $\left(\mathrm{Y}_{0}\right){ }^{7}$ In studies that rely on cross-sectional data at the level of the job seeker, the above-mentioned conclusion does not follow. It is possible and likely that the researcher does not observe an aspect of the job application letter which is important in firms' selection decision as well as determining the decision to either enroll into training or to disclose information on course participation. If this is the case, the CIA assumption is violated, because the outcome is correlated with the treatment status of a job application.

Second, in this design the allocation of job offers to the treatment was entirely under the control of the researcher, which is relevant given potential changes in the search intensity and changes in aspirations. Controlling for search intensity is important since program participation is time consuming and therefore search intensity may be lower (the so-called

\footnotetext{
${ }^{7}$ Recall that all aspects of the job application letter were held constant across treatment status.
} 
"locking-in effect of ALMP"). As a consequence, participation in a policy measure may in fact increase the duration of unemployment (Lalive, Van Ours and Zweimüller, 2002). This effect is ruled out in our design. Controlling for aspiration levels is relevant because participation in a policy measure may not only improve human capital but also aspiration levels. In particular, it might happen that people will have higher aspiration levels or higher reservation wages after completing the computer course than before starting the course. ${ }^{8}$ As a consequence, it may be that previous participants do no longer apply to jobs for which they would have applied for in case of non-participation. This effect cannot be controlled for in usually available data. The present method, however, does control for this effect: first because the application process is exogenous, second because no subject refused to sign a suggested application.

Existing evaluation studies based on cross-section data at the level of the individual typically contain only little if any information at the level of the vacancy. This implies that it is not possible to condition on the type of vacancy in the evaluation. The consequence is that it is not possible to discuss the causal effect of training on the probability of an invitation to a job interview. ${ }^{9}$

\section{Results}

In this section we describe the dataset, report estimates referring to the effect of basic computer course certificates on the chances of getting a job interview and investigate the heterogeneity in the effect of computer programs along two dimensions: skills required on the new job and individual background of the job seeker.

\subsection{Data}

The study was conducted in Zurich between December 1999 and March 2000. We contacted a total of about 100 individuals who were taking part in a total of 12 computer

\footnotetext{
${ }^{8}$ Korpi (1997) shows that ALMP participants indicate a higher subjective well-being than the openly unemployed who do not attend such a program. If subjective well-being is taken as a proxy for utility attached to the labour market status of being a program participant, this evidence suggests that program participants may be more demanding with respect to the quality of a job in the regular labour market compared to unemployed who are not participating in a program. This will decrease the likelihood that a job offer will be accepted by a program participant. It is in this sense that ALMPs may decrease the likelihood of accepting a regular job.

${ }^{9}$ Instead, such studies identify the causal effect of training on invitations and on the process of finding a suitable job offer. Of course, this effect may be of interest. However, in discussing the effects of skill enhancement on labour market success, this combined effect is not informative. If it is the case that training improves the process of finding job offers instead of enhancing computer skills, one might think about sending job seekers to programs aiming at improving job search skills instead of computer skills.
} 
courses. These courses were organised by the three leading providers of official ALMP courses in Zurich. 20 individuals expressed an initial interest in participating in the study. Five individuals decided against participation due to reasons unknown to us. We decided to reject five additional candidates because they were either (i) older than 60, (ii) looking for a very specific type of position that was in very short supply (i.e. musician), or (iii) were under the impression that we would advise them in job search. We ended up with a group of 10 individuals. A total of 191 job applications was sent out, 95 without computer course certificate, 96 with computer course certificate. On average, we sent out the treated application 21 days after sending out the control application. The time span between the date of publishing and the date of sending out the application was not more than one week.

The data contain detailed information about the type of job offer. The first type of information refers to skills required on the vacancy: computer skills, knowledge of a second language and ability to work in a team. These three variables were coded as dummy variables, taking the value 1 if the job offer mentions the item and 0 otherwise. Second, a distinction was made between white-collar jobs and blue collar jobs. Third, there is information about the industry of the firm seeking to hire (government, retail, and other services are the largest three industries), hours of work (as a share of a full time job), the size of the job advertisement in the newspaper $\left(\right.$ in $\mathrm{cm}^{2}$ ), and the date when the vacancy was published. The last characteristic is important because all treated applications were sent out later than the control applications. These characteristics are the set of observables $\mathrm{x}_{\mathrm{J}}$ used in this study.

With respect to individuals, the data are informative on education, age, sex, previous work history, quality of the application, etc. As the data contain repeated observations for each individual, both in the treated and in the non-treated state, it is possible to account for such individual differences by way of person effects.

The dependent variable is whether an application letter leads to an invitation within three weeks after sending out the job application. We find that $83 \%$ of the firms responded within this time period - evidence that the response period was chosen sufficiently long. Note that the fraction of missing responses was identical across treatment stati. The variable "invitation to a job interview" is coded as a dummy taking the value 1 if the hiring firm invites the job seeker, and 0 otherwise. Note that the 0 -outcome refers to the response that the firm does not wish an interview (76\% of all zero entries), the firm wants further information ( $4 \%$ ), and no response on the part of the hiring firm (20\%). 


\subsection{Effect of Treatment on the Treated}

The choice of the appropriate estimation strategy was guided by the trade-off between bias and variance. Non-parametric estimators, such as the method of matching, have the advantage - compared to parametric approaches - that no assumptions beyond CIA stated in (2) need to be invoked. This implies that the bias due to misspecification of the econometric model is reduced. However, it is well known that non-parametric estimators are biased in small samples. Moreover, non-parametric estimators are characterized by a slow speed of convergence to the asymptotic distribution. Considering the fact that the number of job applications in this study is small, we report estimates based on a parametric estimator. ${ }^{10}$

The dependent variable, invitation to a job interview, is a binary variable. We apply a linear probability model to this indicator because there is no need to assume a specific functional form for the error term (Moffitt, 1999). Objections against the linear probability model include that it may produce fitted values outside the zero-one range, and that errors are heteroskedastic. ${ }^{11}$ The first concern cannot be accounted for. Nevertheless, it is true that the linear probability model performs quite well near the sample average of the dependent variable. We report robust standard errors that allow not only for the known form of heterogeneity in the linear probability model but also for additional unknown types of heterogeneity (White, 1980).

Table 1 reports results regarding the effect of a computer course certificate on the probability of invitation to a job interview based on a linear probability model. All estimates control for individual effects and the observed characteristics of the vacancy mentioned in the previous subsection. ${ }^{12}$ Column A reports an estimate of the effect of treatment on the treated based on the assumption that the effect of the course certificate neither differs by individual nor by type of job offer.

According to the estimate in Column A, the effect of the computer course certificate on the success of job applications was negative but not significantly different from zero. The point estimate suggests a reduction of the probability of being invited for a job interview by $3.3 \%$ if a computer course certificate is added to the application. However, the result in Column A may be biased because the underlying assumption is that the treatment effect is constant across individuals and jobs. Therefore, it is important to relax this assumption.

\footnotetext{
${ }^{10}$ See Heckman et al. (1998) for a discussion of the matching estimator.

${ }^{11}$ Aldrich and Nelson (1984) analyze the properties of the linear probability model in detail.

${ }^{12}$ For full estimation results see the working paper version of this study, Falk et al. (2002).
} 
Table 1. The effect of a computer course certificate on invitation to a job interview Dependent variable: Probability of being invited to a job interview

\begin{tabular}{lccc}
\hline & $\mathrm{A}$ & $\mathrm{B}$ & $\mathrm{C}$ \\
\cline { 2 - 4 } Average effect of treatment on the treated & -.033 & & -.052 \\
& $(.047)$ & & \\
Average effect of treatment for vacancies & & & \\
that & & $.094)$ \\
$\ldots$ do not mention computer skills & & $(.061)$ & \\
& & -.195 & \\
$\ldots$ do mention computer skills ${ }^{\text {a) }}$ & & $.093)^{* *}$ & Yes \\
& & & Yes \\
\hline Control Variables & Yes & Yes & 191 \\
Individual Fixed Effects & 191 & 191 & 0.24 \\
\hline Observations & 0.25 & 0.27 & \\
Adjusted R-squared & & & \\
\hline \hline
\end{tabular}

Notes: $\quad$ Robust standard errors $(\mathrm{A}, \mathrm{B})$ or bootstrap standard errors $(\mathrm{C})$ in parentheses .

$*, * *, * * *$ denote significance at the $10 \%, 5 \%$, and $1 \%$ level.

Control variables: computer skills, second-language, team skills, date vacancy was published, size, work hours, skill level, position, industry, and 10 individual effects. See Falk et al. (2002) for the respective coefficients.

A: Assumes constant treatment effect.

B: Allows for heterogeneity of the treatment effect with respect to "computer skills" only.

C: Allows for full heterogeneity of the treatment effect with respect to all variables.

a) Measured relative to "job does not mention computer literacy".

Source: Own calculations.

Column B reports results allowing for differences in the estimated effect of computer courses depending on whether or not the job requires 'computer skills'. The estimates in column B suggest that the effect of computer training on jobs that do not require computer skills is slightly positive but insignificant. Interestingly the effect for jobs that do require computer skills is significantly lower than the effect for jobs that do not require computer skills: The 'invitation probability' drops by $19.5 \%$ if job seekers disclose information on the recent completion of a basic computer course.

While this result appears puzzling at first, a potential explanation is that certificates actually convey two separate and opposing types of information. The first type of information refers to the new skill acquired and is likely to increase invitations. The second type of information is that the job seeker does not have prior work experience with the computer and that therefore the level of computer education is in fact rather low. This information may have a negative impact on the success of job applications. It is plausible that for some jobs, the first, positive effect dominates whereas for other types of jobs the second, negative effect 
dominates. The negative effect will, for instance, dominate in the case of vacancies stating computer skills as a requirement to do the job.

Column B shows that heterogeneity in the effect of computer training courses on invitation to a job interview is important. Column $\mathrm{C}$ in Table 1 therefore reports the estimated average effect of treatment on the treated based on a linear probability model allowing for heterogeneity in the treatment effect along all observed dimensions. This means that the treatment indicator is interacted with all observed characteristics of the vacancy as well as with the 10 person effects. The effect displayed in the table is the product of these separate treatment effects with the average of the characteristic in the sample with treatment. This is an estimator of the population effect of treatment on the treated defined in (4) (see Falk et al. (2002) for an exact description of the procedure used).

The results that allow for differences in the effect along all observed dimensions suggest that the effect of training on labour market success is negative but insignificant. The estimated average effect of treatment on the treated individuals is slightly smaller than the effect reported in Column A, but the difference is neither statistically significant nor quantitatively important. ${ }^{13}$ This means that, in the present context, heterogeneity in the treatment effect does not bias results based on a model assuming homogeneous treatment effects.

\section{Conclusion}

The main difficulty in the evaluation of social programs is to obtain credible estimates for the 'counterfactual', i.e., information for participants on the outcome in the state of nonparticipation. In this paper we suggest a new approach that allows assessing the effect of a program on invitation to a job interview. Job invitation is a convincing and meaningful indicator for the success of active labour market policies since it sheds light on the first stage of process by which programs may affect re-integration. Furthermore, invitation to a job interview can be observed both during and after the program for participants. Thus, it is possible to identify the effect of programs on invitations conditional on all observed or unobserved individual characteristics.

The present study shows that this new approach to program evaluation is operational. We find that the average effect of computer training programs on invitation to a job interview is negative but insignificant. Moreover, our findings indicate that there is a significant

\footnotetext{
${ }^{13}$ Note, that allowing for heterogeneous treatment effects does not improve the fit of the model as indicated by the reduction in the adjusted $\mathrm{R}^{2}$ from .25 to .24 .
} 
negative impact of the program for vacancies that require good computer skills. This result is counterintuitive on first sight. A possible explanation, however, is that the participation in a very basic computer course may actually inform the hiring firm about the absence rather than about the presence of profound computer skills.

Future work should implement this new approach to program evaluation on a larger scale. In addition to evaluating the overall impact of particular programs this would also allow calculating individual treatment effects. The majority of the datasets that are currently used in order to evaluate active labour market programs allow estimating only the average causal effect of a program for specific groups of individuals. In contrast since our method provides information on several treated and control applications per individual it is possible to address the important question of heterogeneity in the average causal effect for each individual who participates in the program. Thus, it is possible to study the distribution of the effects of the program across individuals. This information is critical in thinking about the implementation or the reform of an ALMP system. Moreover, knowing both individual treatment effects and individual characteristics of the participants (like sex, age, education record, unemployment record) allows to characterize those groups of individuals for whom program participation is beneficial, neutral or even counterproductive. This is of central importance for an optimal targeting of policies. 


\section{References}

Aakvik, A., Heckman, J. J., Vytlacil, Edward (2000), Treatment Effects for Discrete Outcomes When Responses to Treatment Vary Among Observationally Identical Persons: An Application to Norwegian Vocational Rehabilitation Programs, NBER Technical Working Paper No. 262.

Agell, J. and Lundborg, P. (1995), Theories of Pay and Unemployment: Survey Evidence from Swedish Manufacturing Firms, Scandinavian Journal of Economics, 97:295-307.

Agell, J. and Lundborg, P. (2003), Survey Evidence on Wage Rigidity and Unemployment: Sweden in the 1990s, Scandinavian Journal of Economics, 105(1): 15-29.

Aldrich, J. and F. Nelson (1984), Linear Probability, Logit and Probit Models, Beverly Hills: Sage Publications.

Behrenz, L. (1998), Who gets the job and why? An Explorative Study of the Recruitment Behaviour of Employers, Doctoral Thesis, Lund University, Sweden.

Bergemann, A., Fitzenberger, B. and S. Speckesser (2000), Multiple Active Labour Market Policy Participation in East Germany: An Assement of Outcomes, Konjunkturpolitik, 195-243.

Calmfors, L., Forslund, A., Hemström, M. (2001), Does Active Labor Market Policy Work? Swedish Economic Policy Review, 8(2): 61-124.

Efron, B. (1993), An Introduction to the Bootstrap, New York: Chapman \& Hill.

Falk, Armin, Lalive, Rafael, and Josef Zweimüller (2002), The Success of Job Applications: A Novel Approach to Program Evaluation, IEW Working Paper No. 131, University of Zurich.

Firth, M. (1981), Racial Discrimination in the British Labor Market, in: Industrial Labor Relations Review 34, 265-272.

Gerfin, M. and Lechner, M. (2002), Microeconometric Evaluation of Active Labour Market Policies in Switzerland, The Economic Journal 112, 854-893.

Heckman, J. J. (1998), Detecting Discrimination, Journal of Economic Perspectives 12, 101116.

Heckman, J. J., LaLonde, R. J. and Smith, J. A. (1999), The Economics and Econometrics of Active Labor Market Programs, Handbook of Labor Economics, Vol. III, ed. by O. Ashenfelter and D. Card. 
Heckman, J. J. and Smith, J. A. (1998), Experimental and Nonexperimental Evaluation, International Handbook of Labour Market Policy and Evaluation, ed. by G. Schmid, J. O’Reilly and K. Schömann, Edward Elgar Publishing, Cheltenham, 37-88.

Heckman, J. J., Ichimura, H., and Todd, P. E. (1997), Matching as an Econometric Evaluation Estimator: Evidence from Evaluating a Job Training Program, Review of Economic Studies, Vol. 64(4).

Holland, P. W. (1986), Statistics and Causal Inference, Journal of the American Statistical Association, 81(396): 945-960.

Korpi, T. (1996), Is Utility Related to Employment Status? Employment, Unemployment, Labor Market Policies and Subjective Well-being among Swedish Youth, Labour Economics 4: 125-147

Lalive, R., Van Ours, J. C. and Zweimüller, J. (2002), The Impact of Active Labor Market Policies on the Duration of Unemployment, mimeo, University of Zurich.

Maddala, G. S. and Jeong, J. (1993), A perspective on application of bootstrap methods in econometrics, in G.S. Maddala, C.R. Rao, and H.D. Vinod, eds., Handbook of Statistics vol. 11, North-Holland, Amsterdam.

Moffit, R. A. (1999), Econometric Methods for Labor Market Analysis, in Ashenfelter, O. and Card, D., Handbook of Labor Economics, Vol. III, North-Holland: Amsterdam.

Neumark, D. M. (1996), Sex Discrimination in Restaurant Hiring: an Audit Study, Querterly Journal of Economics 111(3): 915-941.

Oberholzer-Gee, F. (2000), Unemployment Stigma and Rational Herding: Hiring Practices in Europe and in the United States, mimeo, University of Pennsylvania.

Riach, P. A. and Rich, J. (1991), Testing for Racial Discrimination in the Labor Market, Cambridge Journal of Economics 15, 239-259.

Riach, P. A. and Rich, J. (1995), An Investigation of Gender Discrimination in Labor Hiring, Eastern Economic Journal 21, 343-356.

Roy, A. D. (1951), Some Thoughts on the Distribution of Earnings, Oxford Economic Papers $3,135-146$.

Rubin, D. A. (1974), Estimating Causal Effects of Treatments in Randomized and Nonrandomized Studies, Journal of Educational Psychology 66, 688-701.

Tyler, John H., Murnane, Richard J. and John B. Willett (2000), Estimating the Labor Market Signaling Value of the GED, Quarterly Journal of Economics, 115(2): 431-68 
Weichselbaumer, D. (2004), Is it Sex or Personality? The Impact of Sex-Stereotypes on Discrimination in Applicant Selection, Eastern Economic Journal, forthcoming.

White, H. (1980), A Heteroskedasticity-consistent Covariance Matrix Estimator and a Direct Test for Heteroskedasticity, Econometrica 48, 817-830. 